\title{
Systematic review and meta-analysis: cholecystectomy and the risk of cholangiocarcinoma
}

\author{
Jianping Xiong ${ }^{1}$, Yaqin Wang ${ }^{2}$, Hanchun Huang ${ }^{1}$, Jin Bian ${ }^{1}$, Anqiang Wang ${ }^{1}$, Junyu \\ Long $^{1}$, Ying Zheng ${ }^{3}$, Xinting Sang ${ }^{1}$, Yiyao $\mathrm{Xu}^{1}{ }^{1}$, Xin $\mathrm{Lu}^{1}$ and Haitao Zhao ${ }^{1}$ \\ ${ }^{1}$ Department of Liver Surgery, Peking Union Medical College Hospital, Chinese Academy of Medical Sciences and Peking \\ Union Medical College (CAMS \& PUMC), Beijing, China \\ ${ }^{2}$ Department of Interventional Radiology, The First Affiliated Hospital of China Medical University, Shenyang, China \\ ${ }^{3}$ State Key Laboratory of Quality Research in Chinese Medicine, Institute of Chinese Medical Science, University of Macau, \\ Macau SAR, China
}

Correspondence to: Yiyao Xu, email: xuyiyao@hotmail.com Xin Lu, email: luxinln@163.com

Haitao Zhao, email: zhaoht@pumch.cn

Keywords: cholecystectomy, cholecystolithiasis, cholangiocarcinoma, biliary tract neoplasms, meta-analysis

Abbreviations: ICC: intrahepatic cholangiocarcinoma, ECC: extrahepatic cholangiocarcinoma

Received: April 16, $2017 \quad$ Accepted: July 19, $2017 \quad$ Published: July 26, 2017

Copyright: Xiong et al. This is an open-access article distributed under the terms of the Creative Commons Attribution License 3.0 (CC BY 3.0), which permits unrestricted use, distribution, and reproduction in any medium, provided the original author and source are credited.

\section{ABSTRACT}

Studies have reported that cholecystectomy may increase the risk of cholangiocarcinoma. However, this association is controversial. Thus, we conducted a systematic review and meta-analysis to explore the relationship between cholecystectomy and the risk of cholangiocarcinoma. Relevant studies were identified by searching PubMed, EMBASE, ISI Web of Science published before February 2017. We used the random effects model proposed by DerSimonian and Laird to quantify the relationship between cholecystectomy and risk of cholangiocarcinoma. Publication bias was evaluated using funnel plots, Begg's and Egger's tests. Subgroup and sensitivity analyses were performed to validate the stability of the results. 16 articles, comprising 220,376 patients with cholecystectomy and 562,392 healthy controls, were included in our research. Our meta-analysis suggested that the risk of cholangiocarcinoma was significantly higher in the cholecystectomized patients in comparison with healthy controls, with heterogeneity among studies (summary odds ratio $[\mathrm{OR}]=0.72$; confidence interval $[\mathrm{CI}]=0.55-0.90 ; \mathrm{I}^{2}=69.5 \%$ ). Additionally, this association was also observed in cohort studies $(\mathrm{OR}=0.83 ; 95 \% \mathrm{CI}=0.73-0.94)$ and case-control studies $(O R=0.60 ; 95 \% C I=0.40-0.80)$. However, When the intrahepatic cholangiocarcinoma and extrahepatic cholangiocarcinoma were analyzed separately, the present study only indicated cholecystectomy was associated with increased the risk of extrahepatic cholangiocarcinoma $(\mathrm{OR}=1.19 ; 95 \% \mathrm{CI}=0.32-2.05)$, rather than intrahepatic cholangiocarcinoma $(O R=1.19 ; 95 \% \mathrm{CI}=0.32-2.05)$. In conclusion, cholecystectomy was associated with a significant $54 \%$ increase in the risk of cholangiocarcinoma, especially in the extrahepatic cholangiocarcinoma.

\section{INTRODUCTION}

Gallstones are abnormal masses of a solid mixture of cholesterol crystals, mucin, calcium bilirubinate, and proteins [1]. Gallstone is the most common gastrointestinal disease. An estimated 10\% of Europeans and Americans are carriers of gallbladder stones [2]. Furthermore, along with the improvement of living standards and population overall life extension, the incidence of cholecystolithiasis seems to be increasing $[3,4]$. Additionally, gallstone is the most expensive gastrointestinal diseases, and become a global health burden [5]. For example, it costs of $\$ 6.5$ billion approximately annually in the U.S [6]. Most of gallstones are silent. However, around $25 \%$ of gallstones are symptomatic and accompanied with severe complications, which need to remove the gallbladder by surgically, usually 
by laparoscopic cholecystectomy [7, 8]. An estimated 700,000 cholecystectomies are conducted annually in the US [3]. Over the past few decades, cholecystectomy has been reported to increase the risk of some types of cancer, including colorectal cancer, liver cancer and pancreatic cancer [9-14]. Recently, studies reported cholecystectomy may increase the risk of cholangiocarcinoma. However, this association is controversial [15-20].

Cholangiocarcinoma, which was first described by Durand-Fardel in 1840, is a malignant tumor originating from bile duct epithelium [21]. Cholangiocarcinoma is the second commonest primary liver cancer, as it accounts for $10 \%-25 \%$ of liver malignant tumors and $3 \%$ of all gastrointestinal neoplasms [22, 23]. Moreover, the incidence of cholangiocarcinoma still has been increasing over the past few decades. Somewhat surprisingly, the epidemiological characteristics between intrahepatic cholangiocarcinoma (ICC) and extrahepatic cholangiocarcinoma (ECC) are different, the incidence of ICC have been increasing; On the contrary, the incidence of ECC have been declining in some parts of the world, such as UK and USA [24]. In the United States, the age-adjusted incidence of ICC increased by $165 \%$, whereas ECC declined by $14 \%$ during the past two decades [25]. Besides, the prognosis of cholangiocarcinoma is particularly poor. The overall 1-, 3- and 5-year relative survival rates are reportedly $25.0 \%, 9.7 \%$ and $6.8 \%$, and almost no changes in recent decades [26]. Thus, to better understand the relationship between cholecystectomy and the risk of cholangiocarcinoma, we conducted a systematic review with meta-analysis of published observational studies.

\section{RESULTS}

\section{Study selection and study characteristics}

Figure 1 shows the process of selecting studies. We obtained 13291 articles through the initial search (8124 from PubMed, 1879 from EMBASE, 3288 from Web of Science), 3120 of which were duplicates. We excluded a further 10274 studies based on title and abstract review. Finally, four studies were further excluded due to providing insufficient information [27-30], we identified 16 eligible observational articles for our meta-analysis [15-20, 31-40].

The main characteristics of the included studies are listed in Table 1. Six studies were performed in China, four in the USA, two in Denmark, one in Greece, one in Swedish, one in Korea and one in Taiwan. All included studies were observational studies and included 12 case-control studies and four cohort studies. The metaanalysis included 220,376 patients with cholecystectomy and 562,392 healthy controls to investigate the effect of cholecystectomy on the risk of cholangiocarcinoma. The data collected in the study ranged from 1965 to 2014 . The NOS scores of the included studies ranged from 5 to
9 , with 12 high quality studies and only four of medium quality (Supplementary Tables 1 and 2).

\section{Association between cholecystectomy and the risk of cholangiocarcinoma}

Four cohort and 12 case-control studies were included to investigate the relationship between cholecystectomy and the risk of cholangiocarcinoma. Six studies reported significantly higher risk of cholangiocarcinoma in patients who had cholecystectomies in comparison with the healthy controls. Only one studies reported cholecystectomy was associated with a decreased risk of cholangiocarcinoma. The remaining of the studies did not show a relationship. The pooled estimate was significant $(\mathrm{OR}=1.54 ; 95 \% \mathrm{CI}=1.15$ 1.94), with significant heterogeneity $\left(\mathrm{I}^{2}=69.5 \% ; p=0.006\right)$ (Figure 2). The present study indicated a $54 \%$ increase in the risk for cholangiocarcinoma among the cholecystectomized patients in comparison with healthy controls. However, this relationship was only observed in $\mathrm{ECC}(\mathrm{OR}=2.31 ; 95 \% \mathrm{CI}$ $\left.=1.34-3.28, \mathrm{I}^{2}=86.3 \%\right)$, rather than ICC $(\mathrm{OR}=1.40 ; 95 \%$ $\left.\mathrm{CI}=0.94-1.87, \mathrm{I}^{2}=68.2 \%\right)($ Table 2$)$.

\section{Subgroup and sensitivity analyses}

The results of the subgroup analyses and sensitivity analyses are shown in Table 2. When the studies from Western countries (USA, Denmark, Greece and Swedish) and Eastern countries (Taiwan, Korea and China) were analyzed, a significant difference was found between the two areas. Patients with cholecystectomy in western countries were more likely to develop cholangiocarcinoma compared to eastern countries (western countries: $\mathrm{OR}=1.71 ; 95 \%$ $\mathrm{CI}=1.19-2.23$ and eastern countries: $\mathrm{OR}=1.17 ; 95 \%$ $\mathrm{CI}=0.65-1.69)$ (Table 2). According to the sensitivity analyses, despite excluding studies that the NOS sources were $<7$, the relationship between cholecystectomy and the risk of cholangiocarcinoma remained stable (Table 2). Additionally, the overall results for the relationships of cholecystectomy to cholangiocarcinoma were maintained when the pooling model was altered (fixed-effects model: $\mathrm{OR}=1.24 ; 95 \% \mathrm{CI}=1.13-1.34$ and random-effects model: $\mathrm{OR}=1.54 ; 95 \% \mathrm{CI}=1.15-1.94)$ (Table 2). Besides, when we sequentially excluded one study in one turn to assess the stability of the results, no study could possibly affect the pooled risk estimate (Figure 3).

\section{Publication bias}

The funnel plot did not reveal substantial asymmetry. Additionally, Begg's and Egger's tests did not identify substantial publication bias $(p>0.05)$ (Figure 4).

\section{DISCUSSION}

The causes of cholangiocarcinoma remain poorly understood. Only a few risk factors for the disease 
Table 1: The main characteristics of the included studies

\begin{tabular}{|c|c|c|c|c|c|c|c|c|}
\hline $\begin{array}{l}\text { Study/Years of } \\
\text { Publication }\end{array}$ & Country & $\begin{array}{l}\text { No. Case/ } \\
\text { control }\end{array}$ & Follow & $\begin{array}{l}\text { Sources of } \\
\text { Controls }\end{array}$ & $\begin{array}{l}\text { Subtype of } \\
\text { cancer }\end{array}$ & $\begin{array}{l}\text { Subtype of } \\
\text { study }\end{array}$ & Adjusted Factors & $\begin{array}{l}\text { Adjusted OR/ } \\
\text { RR }(95 \% \mathrm{CI})\end{array}$ \\
\hline Lee.2015 & korea & $276 / 452$ & $2007-2013$ & Hospital & $\mathrm{CC}$ & Case-control & $\begin{array}{l}\text { Cigarette smoking, heavy alcohol consumption, obesity, } \\
\text { choledocholithiasis, cholecystolithiasis, hepatolithiasis, } \\
\text { ulcerative colitis, alcoholic liver disease, thyroid disease, } \\
\text { chronic pancreatitis,pypertension, diabetes mellitus, HBV } \\
\text { infection, HCV infection, liver fluke infestation }\end{array}$ & $1.38(0.67,2.84)$ \\
\hline Zhang.2014 & China & $127 / 254$ & 1993-2013 & Hospital & ICC & Case-control & $\begin{array}{l}\text { Age,sex,BMI,Smoking, Alcohol consumption,HBV } \\
\text { infection,HCV,Liver cirrhosis. }\end{array}$ & $1.53(0.52,4.49)$ \\
\hline Chow.1999 & Denmark & $17715 / 42461$ & $1977-1989$ & Population & $\mathrm{CC}$ & Cohort & age and gender & $1.12(0.81,1.43)$ \\
\hline WELZEL.2007 & USA & $1084 / 102782$ & 1993-1999 & Population & $\mathrm{CC}$ & Case-control & $\begin{array}{l}\text { age,sex,race/ethnicity, cholecochal cysts, cholangitis, } \\
\text { biliary cirrhosis, cholelithiasis, cholecystolithiasis, } \\
\text { choledocholithiasis, liver flukes, alcoholic liver } \\
\text { disease,nonspecific cirrhosis,HCV infection, diabetes } \\
\text { mellitus type II, crohn's disease, ulcerative colitis, } \\
\text { duodenal ulcer, chronic pancreatitis, smoking, obesity }\end{array}$ & $5.4(3.9,7.5)$ \\
\hline Chen.2014 & Taiwan & $5850 / 62180$ & $2000-2014$ & Population & $\mathrm{ECC}$ & Cohort & sex, age and number of comorbidities & $2.22(0.91,5.41)$ \\
\hline Tao.2009 & China & $188 / 380$ & $1998-2008$ & Hospital & $\mathrm{CC}$ & Case-control & age, gender, diabetes mellitus & $3.6(0.9,15.1)$ \\
\hline WELZEL.2006 & Denmark & $764 / 3056$ & $1978-1991$ & Population & ICC & Case-control & $\begin{array}{l}\text { Alcoholic liver diseases, nonspecific cirrhosis, cholangitis, } \\
\text { choledocholithiasis, inflammatory bowel disease, diabetes, } \\
\text { obesity }\end{array}$ & $1.56(0.65,3.73)$ \\
\hline Cai.2011 & China & $313 / 608$ & $2000-2004$ & Hospital & $\mathrm{ECC} 1$ & Case-control & $\begin{array}{l}\text { choledocholithiasis, hepatolithiasis, cholecystolithiasis, } \\
\text { biliary ascariasis, liver fluke and liver schistosomiasis } \\
\text { were the risk factors for HC, while HBV infection, HCV } \\
\text { infection, PSC, UC, alcoholic liver disease, type II diabetes } \\
\text { mellitus,alcohol and smoking }\end{array}$ & $7.01(1.90,25.95)$ \\
\hline Zhou.2013 & China & $239 / 478$ & 1999-2011 & Hospital & $\mathrm{ECC}$ & Case-control & $\begin{array}{l}\text { sex, age (as continuous variable), liver cirrhosis, } \\
\text { cholecystolithiasis, choledocholithiasis, hepatolithiasis, } \\
\text { diabetes mellitus and family history of other cancer. }\end{array}$ & $4.04(1.58,10.31)$ \\
\hline CHALASANI. 2000 & USA & $26 / 87$ & 1991-1998 & Hospital & $\mathrm{CC}$ & Case-control & PSC and geographic location. & $7.11(2.71,18.67)$ \\
\hline Liu.2011 & China & $87 / 288$ & $2000-2008$ & Hospital & $\mathrm{CC}$ & Case-control & $\begin{array}{l}\text { HBV infection, HCV infection, and liver fluke infestation, } \\
\text { Diabetes mellitus, hypertension, alcohol, smoking, }\end{array}$ & $0.76(0.46,1.24)$ \\
\hline Kuper.2001 & Greece & $6 / 360$ & 1995-1998 & Hospital & $\mathrm{CC}$ & Case-control & $\begin{array}{l}\text { Years of schooling, tobacco smoking, excessive alcohol } \\
\text { consumption or coffee drinking }\end{array}$ & $2.39(0.27,21.22)$ \\
\hline Shaib.2007 & USA & $248 / 236$ & 1992-2002 & Hospital & $\mathrm{CC}$ & Case-control & $\begin{array}{l}\text { race, age, gender, } \mathrm{HCV}, \mathrm{HBV} \text { markers, and mild/moderate } \\
\text { alcohol drinking. }\end{array}$ & $1.1(0.6,2.2)$ \\
\hline Nogueira.2014 & USA & $118 / 3681$ & $1992-2005$ & Population & $\mathrm{CC}$ & Cohort & age and gender & $1.19(0.98,1.43)$ \\
\hline Nordenstedt.2012 & Swedish & $192960 / 345251$ & $1965-2008$ & Population & $\mathrm{CC}$ & Cohort & age, sex and gender & $1.28(1.14,1.43)$ \\
\hline Peng.2011 & China & $98 / 126$ & 2002-2009 & Hospital & ICC & Case-control & $\begin{array}{l}\text { HBV infection, cirrhosis, hepatolithiasis, } \\
\text { choledocholithiasis, cholecystolithiasis, and liver fluke } \\
\text { infestation, Diabetes mellitus, Hypertension }\end{array}$ & $1.08(0.42,2.81)$ \\
\hline
\end{tabular}

ICC, intrahepatic cholangiocarcinoma. ECC, extrahepatic cholangiocarcinoma. HBV, hepatitis B virus. HCV, hepatitis C virus. RR, relative risk. OR, odds ratio. CI, confidence interval.

have been identified. These include primary sclerosing cholangitis, hepatolithiasis, bile-duct cysts and parasitic infections [41]. Many recent meta-analyses have identified additional factors that may affect the risk of cholangiocarcinoma, including hepatitis B or C, obesity, diabetes mellitus, cirrhosis, alcohol consumption, smoking [42-46]. To our knowledge, this is the first comprehensive meta-analysis to investigate the relationship between cholecystectomy and the risk of cholangiocarcinoma. 16 studies were identified to examine the effect of cholecystectomy on the risk of cholangiocarcinoma and found that the risk of cholangiocarcinoma was significantly higher in 220,376 patients with cholecystectomy compared with 562,392 healthy populations $(\mathrm{OR}=0.72 ; 95 \% \mathrm{CI}=$ $0.55-0.90$ ), with significant heterogeneity among studies. This effect also was observed in cohort and case-control studies. When the analysis was stratified by geographic area, this effect was more pronounced in Eastern countries in comparison with Western countries. However, When the ICC and ECC were analyzed separately, the present study only indicated cholecystectomy was associated with increased risk of $\mathrm{ECC}(\mathrm{OR}=1.19 ; 95 \% \mathrm{CI}=0.32-2.05)$, rather than $\mathrm{ICC}(\mathrm{OR}=1.19 ; 95 \% \mathrm{CI}=0.32-2.05)$.

Our study only demonstrated an association between cholecystectomy and an increased risk of cholangiocarcinoma; the data cannot establish a causative role for cholecystectomy in this regard. However, if such a causative role is present, possible mechanisms could be the following. First, several authors consider it as the effect of gallstones, rather than the ensuing cholecystectomy, which results in cancer. Early study indicated gallstones may increase the risk of cholangiocarcinoma, especially in ECC $[15,47,48]$. Second, removal of the gallbladder leads to the accumulation of bile and secondary bile acids, and secondary bile acids was associated with increased in the presence of gallstones [49-51]. Additionally, previous studies also reported secondary bile acids can enhance tumor formation in the liver [52]. Because both cholangiocytes and hepatocytes differentiate from the same progenitor cells, similar to the carcinogenesis 
of hepatocytes [53], secondary bile acids might induce carcinogenesis in cholangiocytes through the same mechanism.

Our study has several strengths. First, it is the first meta-analysis with a large sample size (220,376 patients with cholecystectomy and 562,392 healthy populations) to evaluate the effect of cholecystectomy on the risk of cholangiocarcinoma. Therefore, the findings may provide us insight into the relationship between cholecystectomy and the risk of cholangiocarcinoma, and these results are of potential interest to the field of cholangiocarcinoma research. Secondly, subgroup and sensitivity analyses were performed to determine the factors that may affect results. It makes our findings more reliable. Third, we performed a comprehensive literature search of the PubMed, EMBASE and Web of Science databases to identify potential studies to investigate the relationships between cholecystectomy and the risk of cholangiocarcinoma. In addition, most of the studies included in our meta-analysis were of high quality. All of these characteristics make the conclusions of our study more convincing.

There are several limitations that should be considered. First, most of the studies included in our meta-analysis were case-control studies, which was prone to generate recall and selection biases. Additionally, the heterogeneity among studies was significant because of different study designs and demographic characteristics inconsistency. Second, the present study only investigated the risk of cholangiocarcinoma in patients with cholecystectomy compared with healthy population. As a result of the restricted number of included studies in the analysis, the risk of cholangiocarcinoma in patients with cholecystectomy compared with gallstone patients was not explored. Third, what is being observed is just an association, which is subject to confounding bias. The established risk factors for cholangiocarcinoma include primary sclerosing cholangitis, hepatolithiasis, bile-duct cysts and parasitic infections [41]. However, only a few
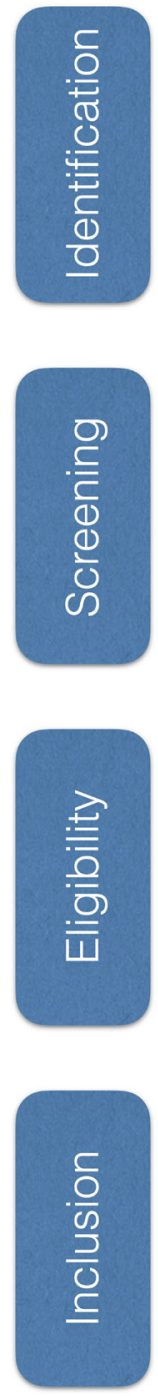

Figure 1: The process of study selection for the meta-analysis. $(\mathrm{n}=253)$

$(n=22)$

Cohort studies $(\mathrm{n}=4)$
Records excluded based on title and $\operatorname{abstract}(n=10274)$

Duplicates studies $(\mathrm{n}=2764)$

\section{Articles identified for further review}

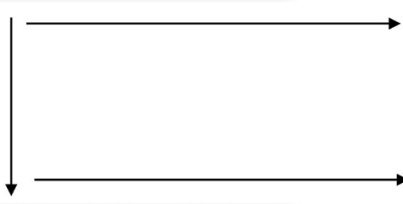

No relevant studies $(\mathrm{n}=207)$

Studies design not case-control, or cohort $(n=24)$

Full text articles assessed for eligibility

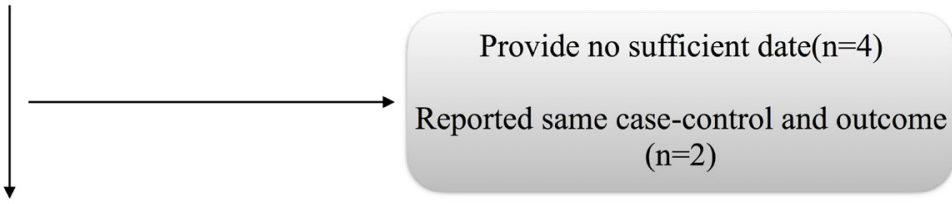

Studies included in final analysis

Case-control studies $(\mathrm{n}=12)$ 
Table 2: Subgroup and sensitivity analyses of the effect of cholecystectomy and the risk of cholangiocarcinoma

\begin{tabular}{|c|c|c|c|c|}
\hline Subgroup & No. of studies & RR $(95 \% C I)$ & I2 value $(\%)$ & $P$ value \\
\hline All studies & 16 & $1.54(1.15,1.94)$ & 86.3 & 0.001 \\
\hline \multicolumn{5}{|l|}{ Subtype of cancer } \\
\hline $\mathrm{ECC}$ & 9 & $2.31(1.34,3.28)$ & 86.3 & 0.001 \\
\hline ICC & 10 & $1.40(0.94,1.87)$ & 68.2 & 0.001 \\
\hline \multicolumn{5}{|l|}{ Geographic areas } \\
\hline West & 8 & $1.71(1.19,2.23)$ & 88.8 & 0.001 \\
\hline East & 8 & $1.17(0.65,1.69)$ & 16.7 & 0.298 \\
\hline \multicolumn{5}{|l|}{ Study deign } \\
\hline Cohort study & 4 & $1.24(1.12,1.35)$ & 0 & 0.618 \\
\hline Case-control study & 12 & $2.31(1.23,3.39)$ & 84.7 & 0.001 \\
\hline \multicolumn{5}{|c|}{ Adjustment for confounders } \\
\hline \multicolumn{5}{|l|}{ Liver fluke infestation } \\
\hline Yes & 5 & $2.68(0.53,4.82)$ & 94.0 & 0.001 \\
\hline No & 11 & $1.24(1.13,1.35)$ & 0 & 0.695 \\
\hline \multicolumn{5}{|l|}{ Cholangitis } \\
\hline Yes & 4 & $5.12(0.64,9.59)$ & 88.9 & 0.001 \\
\hline No & 12 & $1.21(1.10,1.31)$ & 0 & 0.449 \\
\hline \multicolumn{5}{|l|}{ Gallstone } \\
\hline Yes & 6 & $3.09(0.80,5.39)$ & 89.7 & 0.001 \\
\hline No & 10 & $1.17(1.02,1.32)$ & 17.6 & 0.281 \\
\hline \multicolumn{5}{|l|}{ Smoking } \\
\hline Yes & 6 & $2.83(0.51,5.16)$ & 92.5 & 0.001 \\
\hline No & 10 & $1.24(1.13,1.35)$ & 0 & 0.610 \\
\hline \multicolumn{5}{|l|}{ Alcohol intake } \\
\hline Yes & 8 & $2.24(0.96,3.53)$ & 89.5 & 0.001 \\
\hline No & 8 & $1.24(1.13,1.35)$ & 0 & 0.431 \\
\hline \multicolumn{5}{|l|}{ Sensitive analyses } \\
\hline High quality studies & 12 & $1.73(1.19,2.28)$ & 84.6 & 0.001 \\
\hline \multicolumn{5}{|c|}{$\begin{array}{l}\text { Fixed-effects vs random-effects } \\
\text { model method }\end{array}$} \\
\hline Fixed-effects model & 16 & $1.24(1.13,1.34)$ & 76.3 & 0.001 \\
\hline Random-effects model & 16 & $1.54(1.15,1.94)$ & 79.7 & 0.001 \\
\hline
\end{tabular}

ICC, intrahepatic cholangiocarcinoma. ECC, extrahepatic cholangiocarcinoma. RR, relative risk; CI, confidence interval

studies adjusted it in their models. Besides, the results of the present study are subject to diagnostic bias. Patients had cholecystectomies are more likely to undergo physical examination and thus might be more likely to have cholangiocarcinoma detected early. Finally, the length of time necessary following a cholecystectomy for any carcinogenic effect to have occurred remains unknown. It is likely that some cases of cholangiocarcinoma included in this research occurred too soon after cholecystectomy [39, 40].

In summary, our meta-analysis indicated that the risk of cholangiocarcinoma was associated with a 54\% increase in patients who had cholecystectomies in comparison with healthy controls, and the relationship was also demonstrated in cohort and case-control studies. However,
When the ICC and ECC were analyzed separately, the present study only indicated cholecystectomy was associated with increased the risk of ECC, rather than ICC. More prospective studies and basic research are still needed to validate the association of cholecystectomy and cholangiocarcinoma risk and the potential mechanisms.

\section{MATERIALS AND METHODS}

\section{Data sources and search strategy}

We searched published reports in the PubMed, EMBASE and Web of Science databases using the following keywords: ("gallstone" OR "cholelithiasis" 
OR "cholecystolithiasis" OR "choledocholithiasis" OR “cholecystectomy" OR "gallbladder surgery") and ("biliary tract cancer" OR "bile duct cancer" OR "biliary tract neoplasms" OR “cholangiocarcinoma"). We placed no restrictions on the language or date of publication.

\section{Eligibility criteria for study selection}

The eligibility criteria were as follows: study design (case control or cohort); cholecystectomy as the exposure factor and cholangiocarcinoma or bile duct cancer or biliary tract cancer as the outcome; and odds ratio (OR)/ risk ratio $(\mathrm{RR})$ values and corresponding 95\% confidence intervals available or sufficient information to calculate them. If two studies reported the same data, we selected the study with the larger sample.

\section{Data abstraction and quality assessment}

Two researchers (Y.W. and A.W.) independently extracted the required information from the selected studies in a standardized manner. We collected the following information from each article: first author's name, year of publication, country of origin, study design (case-control or cohort), number of participants, duration of follow-up, sources of controls, adjustment for confounding variables, and OR/RR values and 95\% CIs.

The Newcastle-Ottawa Scale (NOS) [54] was used to evaluate the quality of the included studies. We assigned quality categories according to the scores of each study. Specifically, NOS scores of $<4,4-6$, and 7-9 indicated low-, medium-, and high-quality studies, respectively [55]. The maximum total score was 9 points. We resolved discrepancies by consensus.

\section{Statistical analyses}

The OR/RR values and corresponding 95\% CIs were used to evaluate the risk of cholangiocarcinoma in with a history of cholecystectomy. We treated hazard ratios as equivalent to RRs. We used the random effects model proposed by DerSimonian and Laird to quantify the relationship between cholecystectomy and the risk of cholangiocarcinoma [56].

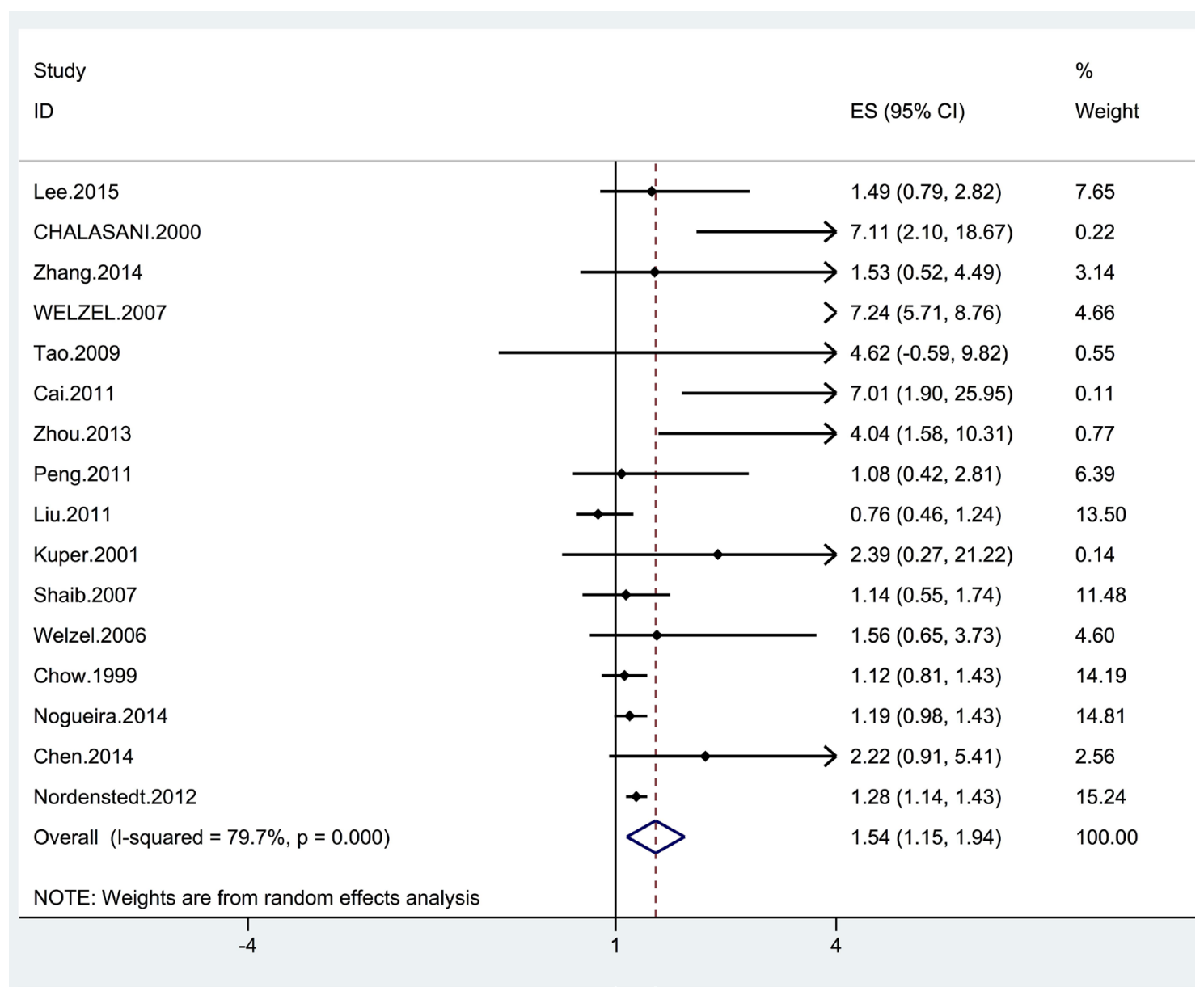

Figure 2: Forrest plot showing the relationship between cholecystectomy and the risk of cholangiocarcinoma. Points represent the risk estimates for each individual study. Horizontal lines represent $95 \%$ confidence intervals, and diamonds represent the summary risk estimates with $95 \%$ confidence intervals. ICC, intrahepatic cholangiocarcinoma. ECC, extrahepatic cholangiocarcinoma. CI, confidence interval. ES, effect size. 


\section{Meta-analysis estimates, given named study is omitted
I Lower Cl Limit
Estimate
I Upper Cl Limit \\ (}

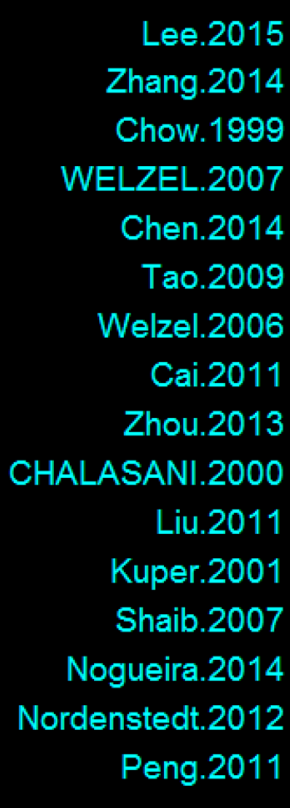

|..
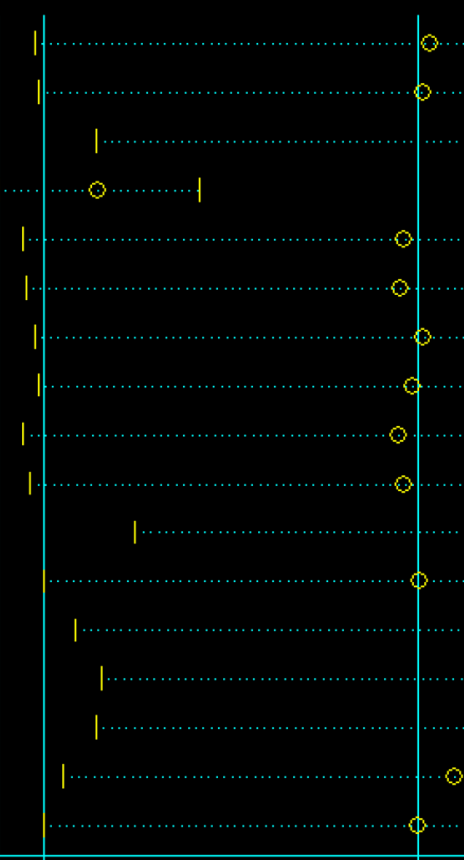

1.10 .15

9

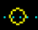

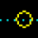

9

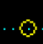

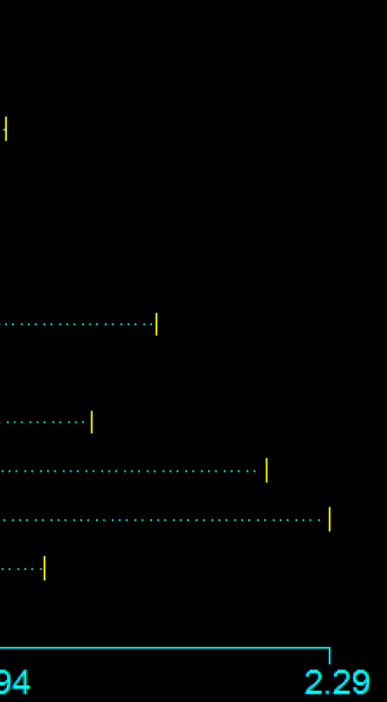

Figure 3: Sensitivity analysis of the association between cholecystectomy and the risk of cholangiocarcinoma.

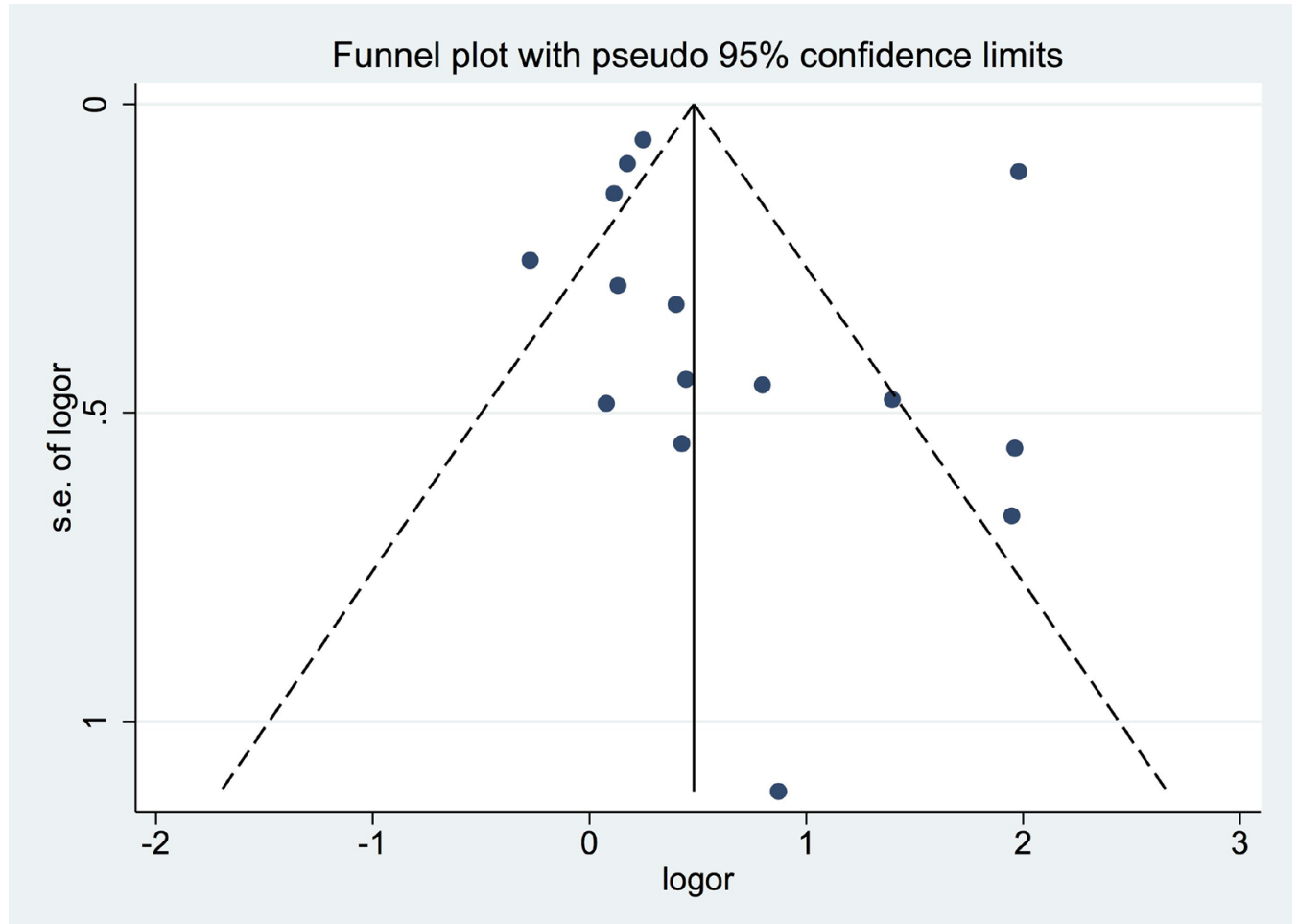

Figure 4: Funnel plot of studies included in the meta-analysis of the relationships between cholecystectomy and the risk of cholangiocarcinoma. Logor: Log odds ratio. SE: standard error. 
The $\mathrm{I}^{2}$ statistic was used to quantify the heterogeneity between studies, and $\mathrm{I}^{2}$ values of $25 \%, 50 \%$, and $75 \%$ represented low, medium, and high heterogeneity, respectively [57]. $P$ values less than 0.1 indicated that clear heterogeneity existed. Publication bias was qualified with funnel plot and Begg's [58] and Egger's [59] tests, and funnel plot asymmetry and $P$ values less than 0.05 indicated the presence of bias.

We also performed subgroup analyses by subtype of cancer, geographic areas, study design and whether liver fluke infestation, cholangitis, gallstones, alcohol intake or smoking were adjusted for in the models. Sensitivity analysis was conducted to assess the stability of the results by sequentially excluding one study in one turn. Additionally, sensitivity analyses were also performed by changing the pooling model (random-effects model or fixed-effects model) and excluded studies that the NOS sources were $<7$.

All statistical analyses were performed using STATA version 12.0 (Stata).

\section{Author contributions}

J.X. designed the study and wrote this manuscript. Y.W. and A.W. searched database and reviewed studies. H.H., J.B, J.L, Y.Z, Y.X., and X.S. collected and analyzed data. X.L. and H.Z. coordinated and provided financial support for this work. All of the authors have read and approved the final manuscript. H.Z. is the guarantor for this study.

\section{CONFLICTS OF INTEREST}

Declaration of personal interests: None

\section{FUNDING}

This work was supported by International Science and Technology Cooperation Projects (2015DFA30650 and 2016YFE0107100), The Capital Special Research Project for the clinical application (Z151100004015170), Capital Special Research Project for Health Development (2014-2-4012), Beijing Nature Science Foundation for Young Scholars Project (7164293), Program for New Century Excellent Talents in University (NCET-11-0288).

\section{REFERENCES}

1. Portincasa P, Moschetta A, Palasciano G. Cholesterol gallstone disease. Lancet. 2006; 368:230-239.

2. Kratzer W, Mason RA, Kachele V. Prevalence of gallstones in sonographic surveys worldwide. J Clin Ultrasound. 1999; $27: 1-7$.

3. Lammert F, Sauerbruch T. Mechanisms of disease: the genetic epidemiology of gallbladder stones. Nat Clin Pract Gastroenterol Hepatol. 2005; 2:423-433.

4. Wang DQ, Cohen DE, Carey MC. Biliary lipids and cholesterol gallstone disease. J Lipid Res. 2009; 50:S406-S411.
5. Shaffer EA. Epidemiology and risk factors for gallstone disease: has the paradigm changed in the 21 st century? Curr Gastroenterol Rep. 2005; 7:132-140.

6. Shaffer EA. Epidemiology of gallbladder stone disease. Best Pract Res Clin Gastroenterol. 2006; 20:981-996.

7. Ransohoff DF, Gracie WA, Wolfenson LB, Neuhauser D. Prophylactic cholecystectomy or expectant management for silent gallstones. A decision analysis to assess survival. Ann Intern Med. 1983; 99:199-204.

8. Stinton LM, Shaffer EA. Epidemiology of Gallbladder Disease: Cholelithiasis and Cancer. Gut Liver. 2012; 6:172-187.

9. Giovannucci E, Colditz GA, Stampfer MJ. A metaanalysis of cholecystectomy and risk of colorectal cancer. Gastroenterology. 1993; 105:130-141.

10. Lin G, Zeng Z, Wang X, Wu Z, Wang J, Wang C, Sun Q, Chen Y, Quan H. Cholecystectomy and risk of pancreatic cancer: a meta-analysis of observational studies. Cancer Causes Control. 2012; 23:59-67.

11. Liu Y, He Y, Li T, Xie L, Wang J, Qin X, Li S. Risk of primary liver cancer associated with gallstones and cholecystectomy: a meta-analysis. PLoS One. 2014; 9:e109733.

12. Fan Y, Hu J, Feng B, Wang W, Yao G, Zhai J, Li X. Increased Risk of Pancreatic Cancer Related to Gallstones and Cholecystectomy: A Systematic Review and MetaAnalysis. Pancreas. 2016; 45:503-509.

13. Ge ZM, Zhao CJ, Wang YM, Qian JB. Cholecystectomy and the risk of esophageal and gastric cancer. Saudi Med J. 2012; 33:1073-1079.

14. Fall K, Ye WM, Nyren O. Risk for gastric cancer after cholecystectomy. Am J Gastroenterol. 2007; 102:11801184.

15. Welzel TM, Graubard BI, El-Serag HB, Shaib YH, Hsing AW, Davila JA, McGlynn KA. Risk factors for intrahepatic and extrahepatic cholangiocarcinoma in the United States: a population-based case-control study. Clin Gastroenterol Hepatol. 2007; 5:1221-1228.

16. Zhang GW, Lin JH, Qian JP, Zhou J. Identification of risk and prognostic factors for patients with clonorchiasisassociated intrahepatic cholangiocarcinoma. Ann Surg Oncol. 2014; 21:3628-3637.

17. Liu ZY, Zhou YM, Shi LH, Yin ZF. Risk factors of intrahepatic cholangiocarcinoma in patients with hepatolithiasis: a case-control study. Hepatobiliary Pancreat Dis Int. 2011; 10:626-631.

18. Shaib YH, El-Serag HB, Nooka AK, Thomas M, Brown TD, Patt YZ, Hassan MM. Risk factors for intrahepatic and extrahepatic cholangiocarcinoma: a hospital-based casecontrol study. Am J Gastroenterol. 2007; 102:1016-1021.

19. Peng NF, Li LQ, Qin X, Guo Y, Peng T, Xiao KY, Chen XG, Yang YF, Su ZX, Chen B, Su M, Qi LN. Evaluation of risk factors and clinicopathologic features for intrahepatic cholangiocarcinoma in Southern China: a possible role of hepatitis B virus. Ann Surg Oncol. 2011; 18:1258-1266.

20. Lee BS, Park EC, Park SW, Nam CM, Roh J. Hepatitis B virus infection, diabetes mellitus, and their synergism for 
cholangiocarcinoma development: a case-control study in Korea. World J Gastroenterol. 2015; 21:502-510.

21. Olnes MJ, Erlich R. A review and update on cholangiocarcinoma. Oncology. 2004; 66:167-179.

22. Vauthey JN, Blumgart LH. Recent advances in the management of cholangiocarcinomas. Semin Liver Dis. 1994; 14:109-114.

23. Shaib Y, El-Serag HB. The epidemiology of cholangiocarcinoma. Semin Liver Dis. 2004; 24:115-125.

24. Taylor-Robinson SD, Toledano MB, Arora S, Keegan TJ, Hargreaves S, Beck A, Khan SA, Elliott P, Thomas HC. Increase in mortality rates from intrahepatic cholangiocarcinoma in England and Wales 1968-1998. Gut. 2001; 48:816-820.

25. Shaib YH, Davila JA, McGlynn K, El-Serag HB. Rising incidence of intrahepatic cholangiocarcinoma in the United States: a true increase? J Hepatol. 2004; 40:472-477.

26. Lepage C, Cottet V, Chauvenet M, Phelip JM, Bedenne L, Faivre J, Bouvier AM. Trends in the incidence and management of biliary tract cancer: a French populationbased study. J Hepatol. 2011; 54:306-310.

27. Ioannou GN. Cholelithiasis, cholecystectomy, and liver disease. Am J Gastroenterol. 2010; 105:1364-1373.

28. Urbach DR, Swanstrom LL, Khajanchee YS, Hansen PD. Incidence of cancer of the pancreas, extrahepatic bile duct and ampulla of Vater in the United States, before and after the introduction of laparoscopic cholecystectomy. Am J Surg. 2001; 181:526-528.

29. Huang YJ, Wu AT, Chiou HY, Chuang MT, Meng TC, Chien LN, Yen Y. Interactive role of diabetes mellitus and female sex in the risk of cholangiocarcinoma: A populationbased nested case-control study. Oncotarget. 2017; 8:66426651. http://doi.org/10.18632/oncotarget.14254.

30. Songserm N, Promthet S, Sithithaworn P, Pientong C, Ekalaksananan T, Chopjitt P, Parkin DM. Risk factors for cholangiocarcinoma in high-risk area of Thailand: role of lifestyle, diet and methylenetetrahydrofolate reductase polymorphisms. Cancer Epidemiol. 2012; 36:e89-94.

31. Chalasani N, Baluyut A, Ismail A, Zaman A, Sood G, Ghalib R, McCashland TM, Reddy KR, Zervos X, Anbari MA, Hoen H. Cholangiocarcinoma in patients with primary sclerosing cholangitis: a multicenter case-control study. Hepatology. 2000; 31:7-11.

32. Tao LY, He XD, Cai L, Liu W, Ji WJ, Zhao L, Zhang SM. [Case-control study of risk factors in cholangiocarcinoma]. [Article in Chinese]. Zhonghua Zhong Liu Aa Zhi. 2009; 31:759-763.

33. Cai WK, Sima H, Chen BD, Yang GS. Risk factors for hilar cholangiocarcinoma: a case-control study in China. World J Gastroenterol. 2011; 17:249-253.

34. Zhou Y, Zhou Q, Lin Q, Chen R, Gong Y, Liu Y, Yu M, Zeng B, Li K, Chen R, Li Z. Evaluation of risk factors for extrahepatic cholangiocarcinoma: ABO blood group, hepatitis B virus and their synergism. Int J Cancer. 2013; 133:1867-1875.
35. Kuper H, Lagiou P, Mucci LA, Tamimi R, Benetou V, Trichopoulos D. Risk factors for cholangiocarcinoma in a low risk Caucasian population. Soz Praventivmed. 2001; 46:182-185.

36. Welzel TM, Mellemkjaer L, Gloria G, Sakoda LC, Hsing AW, El Ghormli L, Olsen JH, McGlynn KA. Risk factors for intrahepatic cholangiocarcinoma in a low-risk population: a nationwide case-control study. Int J Cancer. 2007; 120:638-641.

37. Nordenstedt H, Mattsson F, El-Serag H, Lagergren J. Gallstones and cholecystectomy in relation to risk of intraand extrahepatic cholangiocarcinoma. Br J Cancer. 2012; 106:1011-1015.

38. Chen YK, Yeh JH, Lin CL, Peng CL, Sung FC, Hwang $\mathrm{IM}$, Kao $\mathrm{CH}$. Cancer risk in patients with cholelithiasis and after cholecystectomy: a nationwide cohort study. J Gastroenterol. 2014; 49:923-931.

39. Nogueira L, Freedman ND, Engels EA, Warren JL, Castro F, Koshiol J. Gallstones, cholecystectomy, and risk of digestive system cancers. Am J Epidemiol. 2014; 179:731-739.

40. Chow WH, Johansen C, Gridley G, Mellemkjær L, Olsen JH, Jr JFF. Gallstones, cholecystectomy and risk of cancers of the liver, biliary tract and pancreas. Br J Cancer. 1999; 79:640-644.

41. Khan SA, Thomas HC, Davidson BR, Taylor-Robinson SD. Cholangiocarcinoma. Lancet. 2005; 366:1303-1314.

42. Palmer WC, Patel T. Are common factors involved in the pathogenesis of primary liver cancers? A meta-analysis of risk factors for intrahepatic cholangiocarcinoma. J Hepatol. 2012; 57:69-76.

43. Zhou Y, Zhao Y, Li B, Huang J, Wu L, Xu D, Yang J, He J. Hepatitis viruses infection and risk of intrahepatic cholangiocarcinoma: evidence from a meta-analysis. BMC Cancer. 2012; 12:289.

44. Wang Z, Sheng YY, Dong QZ, Qin LX. Hepatitis B virus and hepatitis $\mathrm{C}$ virus play different prognostic roles in intrahepatic cholangiocarcinoma: A meta-analysis. World J Gastroenterol. 2016; 22:3038-3051.

45. Li M, Li J, Li P, Li H, Su T, Zhu R, Gong J. Hepatitis B virus infection increases the risk of cholangiocarcinoma: a meta-analysis and systematic review. J Gastroenterol Hepatol. 2012; 27:1561-1568.

46. Jing W, Jin G, Zhou X, Zhou Y, Zhang Y, Shao C, Liu $\mathrm{R}, \mathrm{Hu} \mathrm{X}$. Diabetes mellitus and increased risk of cholangiocarcinoma: a meta-analysis. Eur J Cancer Prev. 2012; 21:24-31.

47. Cai H, Kong WT, Chen CB, Shi GM, Huang C, Shen $\mathrm{YH}$, Sun HC. Cholelithiasis and the risk of intrahepatic cholangiocarcinoma: a meta-analysis of observational studies. BMC Cancer. 2015; 15:7.

48. Nordenstedt H, Mattsson F, El-Serag H, Lagergren J. Gallstones and cholecystectomy in relation to risk of intraand extrahepatic cholangiocarcinoma. Br J Cancer. 2012; 106:1011-1015. 
49. Pomare EW, Heaton KW. Bile salt metabolism in patients with gallstones in functioning gallbladders. Gut. 1973; 14:885-890.

50. van der Linden W, Katzenstein B, Nakayama F. The possible carcinogenic effect of cholecystectomy. No postoperative increase in the proportion of secondary bile acids. Cancer. 1983; 52:1265-1268.

51. Pomare EW, Heaton KW. The effect of cholecystectomy on bile salt metabolism. Gut. 1973; 14:753-762.

52. Cameron RG, Imaida K, Tsuda H, Ito N. Promotive effects of steroids and bile acids on hepatocarcinogenesis initiated by diethylnitrosamine. Cancer Res. 1982; 42:2426-2428.

53. Tanaka M, Tanaka H, Tsukuma H, Ioka A, Oshima A, Nakahara T. Risk factors for intrahepatic cholangiocarcinoma: a possible role of hepatitis B virus. J Viral Hepatitis. 2010; 17:742-748.

54. Stang A. Critical evaluation of the Newcastle-Ottawa scale for the assessment of the quality of nonrandomized studies in meta-analyses. Eur J Epidemiol. 2010; 25:603-605.
55. Zhang YP, Li WQ, Sun YL, Zhu RT, Wang WJ. Systematic review with meta-analysis: coffee consumption and the risk of gallstone disease. Aliment Pharmacol Ther. 2015; 42:637-648.

56. DerSimonian R, Laird N. Meta-analysis in clinical trials. Control Clin Trials. 1986; 7:177-188.

57. Higgins JPT, Thompson SG. Quantifying heterogeneity in a meta-analysis. Stat Med. 2002; 21:1539-1558.

58. Begg CB, Mazumdar M. Operating characteristics of a rank correlation test for publication bias. Biometrics. 1994; 50:1088-1101.

59. Egger M, Davey Smith G, Schneider M, Minder C. Bias in meta-analysis detected by a simple, graphical test. BMJ. 1997; 315:629-634. 